WORKING PAPER 3/2018

SELF-SELECTION AND TREATMENT EFFECTS

IN MACROECONOMICS: REVISITING THE

EFFECTIVENESS OF FOREIGN EXCHANGE INTERVENTION

Victor Pontines

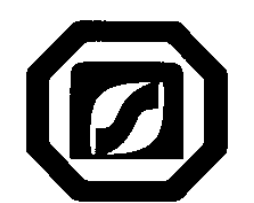

The South East Asian Central Banks (SEACEN) Research and Training Centre (80416-M) Kuala Lumpur, Malaysia 
WORKING PAPER 3/2018

SELF-SELECTION AND TREATMENT EFFECTS

IN MACROECONOMICS: REVISITING THE

EFFECTIVENESS OF FOREIGN EXCHANGE INTERVENTION

Victor Pontines*

March 2018

* Senior Economist, The South East Asian Central Banks (SEACEN) Research and Training Centre. Address: Level 5, Sasana Kijang, Bank Negara Malaysia, No. 2. Jalan Dato' Onn 50480 Kuala Lumpur, Malaysia. Email: vpontines@seacen.org 


\begin{abstract}
Along the lines of the treatment effects literature, this paper empirically revisits the issue of the so-called "intervention effect", i.e., the effectiveness of official foreign exchange intervention on the movement of the exchange rate. We extended in a continuous treatment setting the inverse probability weights estimator developed by Jorda and Taylor (2015) and Angrist, Jorda and Kuersteiner (forthcoming) to control for self-selection bias. We then illustrate the application of this technique by examining the effectiveness of official daily interventions by Japanese monetary authorities in the JPY/USD market. In accordance with existing evidence using this intervention data, this paper finds that periods of intervention characterized by large, infrequent and sporadic interventions are effective in moving the changes in the exchange rate in the desired direction. We also find evidence that the intervention effect does not last longer than two days after the intervention takes place.
\end{abstract}

Keywords: $\quad$ Foreign Exchange Intervention, Self-selection, JPY/USD Exchange Rate, Censored Data, Tobit, Inverse Probability Weights, Local Projections

JEL Classification: C14, C32, E52, E58, F31

Disclaimer: This Working Paper should not be reported as representing the views of SEACEN or its member central banks/monetary authorities. The views expressed in this Working Paper are those of the author(s) and do not necessarily represent those of SEACEN or its member central banks/monetary authorities. 


\section{Table of Contents}

\section{Page}

Abstract

1. Introduction 1

2. Data 2

3. Estimation Strategy 4

3.1 Intervention Reaction Function 5

3.2 Inverse Probability Weights 5

3.3 Outcome Equation - Linear Local Projections (LPs)
with Inverse Probability Weights

4. Results 7

4.1 Baseline Estimates

4.2 Linear LP with Inverse Probability Weights 9

4.3 Robustness Tests 10

5. Conclusion 10

$\begin{array}{ll}\text { References } & 13\end{array}$

\section{List of Tables and Figures}

Table 1: Official Japanese Intervention, 1 January 1999

to December 31, 2011

Table 2: Intervention Reaction Functions: Tobit Estimates 17

Table A1: Intervention Reaction Functions: OLS Estimates 18

Figure 1: Panel A. Daily Intervention Volume

(in millions of USD), 1 January 1999 to March 31, 2004

Panel B. Daily Intervention Volume

(in millions of USD), 1 January 1999 to December 31, 2011

Figure 2: Average Causal Effect of Intervention on Changes

in Yen-US Dollar Rate Estimated using LP (9 lags

Figure 3: Average Causal Effect of Intervention on Changes in Yen-US Dollar Rate Estimated using LP with Inverse Propensity Weights (9 lags)

Figure A1: Average Causal Effect of Intervention on Changes i

in Yen-US Dollar Rate Estimated using LP with

Inverse Propensity Weights (4 Lags)

Figure A2: Average Causal Effect of Intervention on Changes

in Yen-US Dollar Rate Estimated using

LP with Inverse Propensity Weights (9 Lags, Box Cox Transform)

Figure A3: Average Causal Effect of Intervention on Changes

in Yen-US Dollar Rate Estimated using LP with Inverse Propensity

Weights (9 Lags, with Squared Contemporaneous Term) 


\title{
SELF-SELECTION AND TREATMENT EFFECTS IN MACROECONOMICS: REVISITING THE EFFECTIVENESS OF FOREIGN EXCHANGE INTERVENTION
}

\author{
By \\ Victor Pontines
}

\section{Introduction}

This paper evaluates the effectiveness of official foreign exchange intervention on the movement of the exchange rate, i.e., the so-called "intervention effect". In line with the concept of "success" or effectiveness in the literature, we examine whether official foreign exchange intervention influence or push the changes in the exchange rate (daily exchange rate returns) in the desired direction. In general, the literature has not reached a definite conclusion on the effectiveness of foreign exchange intervention on the changes in the exchange rate, at most times suggesting the absence of any relation (e.g., Baillie and Humpage, 1992; Baillie and Osterberg, 1997; Hillebrand and Schnabl, 2004; Neely, 2008; Galati and Disyatat, 2005; Sarno and Taylor, 2001). Also, the survey papers of Edison (1993) and Almekinders (1995) conclude the lack of a firm relationship between intervention and exchange rate returns. In contrast, Dominguez and Frankel (1993), Ito (2003), Fatum and Hutchison (2006), Fatum and Hutchison (2010) find evidence that foreign exchange intervention tends to be effective when intervention operations are large and infrequent. Furthermore, based on results of surveys conducted among central banks, intervention is implicitly supported because it is generally believed that it is a useful and effective instrument (Neely, 2008).

Indeed, achieving a clear identification of the causal effect of this policy instrument on the changes in the exchange rate is a very challenging empirical issue for any analysis of such a policy. For instance, because authorities may be prompted to intervene when the exchange moves in the contrary direction, one of the ways in which the literature has addressed this simultaneity bias is to adopt a two-stage estimation (e.g., Kearns and Rigobon, 2005; Galati and Melick, 2002; Galati et al., 2005; Fatum and Yamamoto, 2014). In this approach, the predicted values obtained from an intervention reaction function estimated in the first-stage is used as an instrumental variable for contemporaneous intervention in the second stage, which then links the changes in the exchange rate to intervention. In this paper, we follow this strategy to control for simultaneity. We also adopt the strategy of modeling the intervention reaction function as a censored variable in view of the non-negligible proportion of zero values in the intervention data (e.g., Almekinders and Eijffinger, 1994; Humpage, 1999; Kim and Sheen, 2002; Rogers and Siklos, 2003; Brandner and Grech, 2005; Adler and Tovar, 2014)

It must be noted, however, that the contribution of this paper to the literature is on how we further address the problem of endogeneity. We employ a modern technique on the treatment effect literature to confront the problem that the decision to officially intervene in the 
foreign exchange market is not taken at random. Specifically, this problem is addressed by rebalancing the observations to effectively create a pseudo-population "as if" the decision to intervene had been taken at random using the "doubly robust" inverse probability weighted (IPW) estimator developed by Jorda and Taylor (2015) and Angrist, Jorda and Kuersteiner (forthcoming). The IPW estimator involves the construction of the inverse probability weights from the estimation in the first stage, and in the second stage, the estimation of the linear Local Projections (LP) of Jorda (2005) using these constructed weights. In this paper, we extend the application of the IPW estimator by constructing the weights in a continuous treatment setting. ${ }^{1}$ To the best of our knowledge, the technique we employ in this study is the first such application that investigates the issue of the effectiveness of foreign exchange intervention.

We illustrate the application of the above technique using official daily amounts of interventions by Japanese monetary authorities in the JPY/USD market. ${ }^{2}$ Ever since Japanese monetary authorities released data on their foreign exchange intervention activities in 2001, several studies have examined the effects of Japanese foreign exchange intervention on daily returns of the JPY/USD exchange rate. Takagi (2014) reviewed 30 studies that examined intervention data for the period April 1991 to March 2004, and reflective of the above general literature on this issue, finds contrasting evidence as to its effectiveness. However, towards the end of his survey, Takagi (2014) suggested that, on average, intervention moves the JPY/USD exchange rate in the desired direction when the scale is large, and intervention is infrequent.

We obtain results that are consistent with the above generalization. Intervention episodes characterized by large, infrequent and sporadic interventions are effective in moving the changes in the exchange rate in the desired or correct direction. Also, in line with the finding by Nagayasu (2004), evidence of an intervention effect does not last longer than two days when an intervention takes place. The paper is structured as follows. The next section gives a description of the Japanese intervention data. The third section discusses the empirical strategies employed in the paper. The fourth section presents the empirical results and robustness tests. The fifth section concludes.

\section{Data}

The period of study is from 1 January 1999 to 31 December 2011 during which all official daily amounts of interventions in the JPY/USD market are sales of JPY against purchases of

\footnotetext{
${ }^{1}$ Following the treatment effects literature, treatment refers to the decision by monetary authorities to intervene in the foreign exchange market. The extension is made in a continuous treatment setting because the actual daily amounts of intervention is used in the construction of the inverse probability weights as opposed to converting the intervention data as an indicator variable that takes on the value of 1 on days when there is intervention and 0 otherwise. More discussion on this aspect follows in subsequent sections.

2 For a related study that corrects for non-random intervention in the JPY/USD market using propensity score and matching techniques, refer to Fatum and Hutchison (2010).
} 
USD. The first column of Table 1 shows that during this period, intervention by Japanese monetary authorities occurred on a total of 167 days. The daily intervention amount ranges from USD 1 million to USD 102 billion, while the average intervention amount is USD 4.1 billion. The extent of intervention on most days of intervention is quite substantial with purchases of USD 1000 million and larger being more prevalent (i.e., 121 days) as compared to 46 days of reported purchases of less than USD 1000 million and only 20 days of reported purchases of less than USD 250 million. $^{3}$

Columns two to four of Table 1 further provide a description of the official daily amounts of intervention by Japanese monetary authorities in the JPY/USD market across three subsamples. Column two shows that only 30 days of intervention occurred during the first four years of the period, with the magnitude of intervention being substantial, i.e., all these days of reported intervention were purchases of USD 500 million and larger. Between January 2003 to March 2004, interventions occurred for 129 days, for which during this sub-sample, the extent of intervention on most days of intervention was quite substantial with purchases of USD 1000 million and larger dominated (i.e., 85 days) as compared to 44 days of reported purchases of USD of less than USD 1000 million and only 20 days of reported purchases of less than USD 250 million. One then notes from this description of the intervention data that while the scale of intervention was relatively large in both sub-periods, the frequency of intervention between the two sub-periods was different. In the first sub-sample (January 1999 to December 2002) interventions were infrequent as opposed to the second sub-sample (January 2003 to March 2004) for which interventions can be described as frequent. This importantly suggests that the two sub-samples represent two contrasting intervention tactics. ${ }^{4}$

Panel A of Figure 1 depicts these two contrasting intervention tactics on the part of Japanese monetary authorities. The figure shows the relatively large amounts of intervention in both sub-samples, averaging USD 5 billion (column 2, Table 1) during the first sub-sample, and USD 2.5 billion (column 3, Table 1) during the second sub-sample. At the same time, the more pronounced clustered occurrence of daily intervention during the second sub-sample as opposed to the first sub-sample observed in Panel A of Figure 1, indicates the more frequent intervention on the part of Japanese monetary authorities during the former.

After the intervention conducted on 16 March 2004, there was six-and-a-half years of no reported intervention, which then ended in September 2010 when Japanese monetary authorities returned to intervene in the JPY/USD market. The last column of Table 1 describes the official daily amounts of intervention by Japanese monetary authorities in the JPY/USD market during the last sub-sample, September 2010 to December 2011. Beyond this subperiod, there has been no reported intervention by Japanese monetary authorities. The magnitude and frequency of intervention conducted by Japanese monetary authorities during this last sub-period was dramatic. Intervention was only carried out on 8 days, but for all these

\footnotetext{
3 This idea of an intervention frequency follows from Fatum and Hutchison (2010).

${ }^{4}$ Fatum and Hutchison (2010) and Takagi (2014) make similar observations.
} 
days of intervention, there were purchases of USD 1000 million and larger, with the average amount of USD 29 billion, and daily intervention amount that ranged from USD 2.9 billion to an astounding USD 102 billion. Aside from the sporadic incidence of intervention during this sub-sample, the sheer scale of the intervention overshadowed the magnitude of intervention in the first two sub-samples (Panel B, Figure 1). The empirical analysis conducted in subsequent sections of this paper is for the entire period under study as well as for these three sub-samples.

\section{Estimation Strategy}

Addressing the problem of endogeneity to clearly isolate the causal effect of foreign exchange intervention is a recognized challenge in the literature. To control for simultaneity, this paper follows the literature by taking a two-stage estimation procedure. In the first stage, an intervention reaction function is estimated and the predicted values from this estimation are used as an instrument for contemporaneous intervention in the second stage. In addition, because a non-negligible proportion of the observations for the dependent variable in the reaction function (i.e., amount of intervention) is zero, the reaction function is modeled as a censored variable with the estimation conducted using a Tobit model. The second stage entails estimating an outcome equation that links the daily returns in the JPY/USD exchange rate to an intervention.

The contribution of this paper is on how it controls for the fact that the decision to intervene is not a random occurrence. To confront this problem, we rely on the recently developed IPW estimator advocated by Jorda and Taylor (2015) and Angrist, Jorda and Kuersteiner (forthcoming). Specifically, inverse probability weights are constructed from the first stage estimation, then the linear LP of Jorda (2005) are employed in the second stage using weights given by the inverse probability weights. In this study, we extend the construction of the inverse probability weights in a continuous treatment setting. ${ }^{5}$ The selfselection bias in intervention is addressed because the observations in the second stage estimation are rebalanced using the inverse probability weights, which then mimics a situation where the decision to intervene had been random. In other words, rebalancing the observations using the constructed inverse probability weights effectively creates a pseudopopulation "as if" the decision to intervene had been taken at random. Finally, by projecting the daily returns of the JPY/USD exchange rate through the linear LP, the effect of intervention on the JPY/USD exchange rate is assessed at each horizon. This summary of the approaches employed in this paper is elaborated below.

\footnotetext{
5 The inverse probability weights of the IPW estimator were originally constructed from a discrete estimation in the first stage.
} 


\subsection{Intervention Reaction Function}

As earlier mentioned, to extract the predicted values to be used as instruments for the second stage estimation as well as to facilitate the construction of the inverse probability weights, an intervention reaction function is estimated in the first stage. The reaction function is modeled as a censored variable, given that all the official intervention operations over the sample period are sales of Japanese yen against US dollar purchases and a non-trivial proportion of zero intervention operations during the same period:

$$
\begin{aligned}
& \mathrm{INT}_{t}=\max \left\{0, \alpha_{0}+\beta_{0} \mathrm{EXR}_{t-1}+\beta_{1} \mathrm{MA}_{21 \mathrm{EXR}} \mathrm{E}_{t-1}+\beta_{2} \mathrm{YEAREXR}_{t-1}+\beta_{3} 125 \mathrm{EXR}_{t,-1}\right. \\
& +\sum_{j=1}^{3} \beta_{4} \mathrm{INT}_{, t-1}+\varepsilon t
\end{aligned}
$$

where INT is the actual intervention amount in billions of USD, EXR is the first-difference of the logarithm of the JPY/USD exchange rate, MA21EXR is the 21-day moving average of the logarithm of the JPY/USD exchange rate, YEAREXR is the 1-year moving average of the logarithm of the JPY/USD exchange rate, 125EXR is the first difference of the logarithm of the JPY/USD exchange rate deviation from an exchange rate target of $125 \mathrm{JPY} / \mathrm{USD}$, and $\varepsilon$ is the error term. The above reaction function is estimated over the full sample period and separately across the three sub-samples using a Tobit model with heteroscedasticity and autocorrelation (HAC) consistent standard errors. The choice of the explanatory variables to include in the above reaction function follows Ito (2003), Ito and Yabu (2007), Fatum and Hutchison (2010) and Fatum and Yamamoto (2014).

\subsection{Inverse Probability Weights}

This sub-section discusses the extension of the construction of the inverse probability weights in a continuous treatment setting. The first-stage estimation of the intervention reaction function provides an appropriate set-up to construct the inverse probability weights designed to simulate a setting in which the decision to intervene is random. If, in the simple case that the dependent variable, INT, in equation (1) is an indicator variable that takes on the value of 1 on days when there is intervention and 0 otherwise, the inverse probability weights are constructed by estimating in the first-stage, the propensity scores or predicted probabilities for each observation in the sample, and then obtaining the inverse of these propensity scores to weight the observations. ${ }^{6}$ Constructing the inverse probability weights in this fashion have

6 Typically, the weights are so called "stabilized" to counter large weights where a few observations drive the results of the analysis. Instead of taking a simple inverse of the propensity scores, stabilized weights are constructed by replacing the numerator (which is 1) by the proportion of the treated observations (for the treatment observations) and the proportion of the control observations (for the control observations). Stabilized weights tend to produce estimates that have smaller variance. 
been carried out in a few recent studies that examine various other issues in macroeconomics and finance. ${ }^{7}$

However, we avoid carrying out the analysis in the above manner as this implies a loss of information with our intervention data. Nonetheless, the weights can still be straightforwardly constructed in a non-discrete treatment such as the case on hand. In this case, conditional densities are obtained from the first stage estimation to construct the inverse probability weights. Robins et al. (2000) recommended that stabilized inverse probability weights in a continuous treatment setting be constructed as follows:

$$
\text { Inverse Probability Weights }=\frac{f(\mathrm{INT})}{f(\mathrm{INT} \mid \mathrm{X})}
$$

where the denominator, also referred to in the treatment-effects literature as the generalized propensity score (GPS), is the conditional density derived from the estimation of equation (1) above. ${ }^{8}$ The numerator is simply the marginal density of INT, and noting that we modeled equation (1) as a censored variable:

$$
f(\mathrm{INT})=\left\{\frac{1}{\sigma} \phi\left(\frac{\mathrm{INT}-\mu}{\sigma}\right)\right\}^{d} \cdot\left\{1-\Phi\left(\frac{\mu}{\sigma}\right)\right\}^{1-d}
$$

Letting $d=1$ denote the censoring indicator for the outcome that the observation is not censored, while $d=0$ indicate a censored observation, equation (3) suggests that the density function has two components. The first term corresponds to the contribution of the uncensored observations to the likelihood, while the second term reflects the contribution to the likelihood of the censored observation.

\subsection{Outcome Equation - Linear Local Projections (LPs) With Inverse Probability Weights}

Once the inverse propensity weights are constructed, the final step is to bring everything together through the estimation of the outcome equation that links the daily returns in the JPY/USD exchange rate to intervention. The estimation of the outcome equation then serves as the second plank of the IPW estimator. The selection-on-observable assumption (or conditional independence assumption (CIA)) is expressed as follows:

$$
\mathrm{EXR} \perp \mathrm{INT} \mid \mathrm{Z}, \quad \text { for all INT }
$$

\footnotetext{
7 For instance, Kuvshinov and Zimmermann (2016) on the estimation of the cost of sovereign default; Bordon et al. (2016) on the role of the business cycle and macroeconomic policies in the impact of structural reforms; Jorda, et al. (2016) on the long-run financial stability risks of real estate lending booms; Diniz (2016) on the effects of fiscal austerity measures.

8 This also follows from the work of Hirano and Imbens (2004) for continuous treatments.
} 
The IPW estimator provides a convenient empirical strategy that automatically converts equation (4) into a causal effect. This involves estimating the following set of $h$-step ahead predictive regressions or linear LP introduced by Jorda (2005):

$$
\mathrm{EXR}_{t+h}=\alpha^{h}+\beta^{h} \widehat{\mathrm{NT}}_{t}+\sum_{i=1}^{p} \gamma_{i}^{h} \mathrm{Z}_{i t}+\epsilon_{t+h}^{h}
$$

where EXR is defined as before, I INT is the intervention substituted by the predicted values from the first-stage estimation as the instrument ${ }^{9}, Z$ include lagged values of EXR and I $\widehat{N T}$ and we set the lag length to nine ${ }^{10}$, and $\epsilon_{t+h}^{h}$ is a prediction error term with $\operatorname{Var}\left(\epsilon_{t+h}^{h}\right)=\sigma^{2, h}$. The linear LP involves the estimation of $h+1$ separate linear regressions. One advantage that the linear LP brings forth and perhaps account for its rising usage in empirical applications is that it is less vulnerable to mis-specification. This is due to the estimation in each horizon involving its own regression as opposed, for instance, to relying on the iteration of previously, possibly mis-specified expectations as one may have in VAR impulse responses.

We estimate equation (5) with weighted least squares (WLS) up to horizon $h=10$ using weights defined by the inverse probability weights in equation (2). In doing so, we simulate a situation of "as if" the decision to intervene had been taken at random by giving a higher weight to observations that have lower probabilities of self-selection in the sample, while less weight to observations that have high probabilities of self-selection. In other words, we create a counterfactual or pseudo-population by according a higher weight to the under-sampled region of the distribution, while a lesser weight to the over-sampled region. Because we are interested in the estimation of the impact on EXR $\mathrm{E}_{t+h}$ with respect to a change in the predicted values of intervention, $\widehat{\mathbb{N T}}$, for $h$ ranging from 1 to 10 , keeping all other variables constant, the estimate of the regression coefficient $\beta^{h}$ at each horizon is then the causal effect of interest, as this denotes the effect of intervention on the changes of the JPY/USD exchange rate.

The technique just laid out above and implemented in the empirical analysis that follows is considered doubly-robust to mis-specification. ${ }^{11}$ The reason being that consistent estimates are still produced even if one of the regression in stages one and two is incorrectly specified. In other words, only one of the two stages of estimation need to be correctly specified to produce consistent estimates.

\section{Results}

\subsection{Baseline Estimates}

We begin by first reporting our baseline estimates of the first-stage intervention reaction function (equation (1)) and the second-stage outcome equation (equation (5)). Ordinary least

\footnotetext{
${ }^{9}$ Adler and Tovar (2014) refer to these predicted values as the shadow intervention values.

${ }^{10}$ Based on the Akaike information criterion.

${ }^{11}$ See Lunceford and Davidian (2004) and Glynn and Quinn (2010) in the case of binary treatments, while Zhang et al. (2016) in the case of continuous treatments.
} 
squares (OLS) were used in the baseline estimations. As mentioned, we conduct all estimations over the full sample period and separately across the three sub-samples. We estimate the first-stage intervention reaction function by first including all explanatory variables in equation (1). The common results across all samples is the insignificance of lagged MA21EXR, lagged YEAREXR and lagged 125EXR. The insignificant explanatory variables are excluded, and a reduced reaction function is re-estimated across all samples. These reduced reaction functions are presented in Table A1. The significant variables for the full sample (column 1) are lagged EXR and the one, two and three period lags of INT, although the significant variables differ across the three sub-samples (columns two to four). The significant variables in the reduced estimates suggest that intervention reacts to the previous day changes in the JPY/USD exchange rate (except in the third sub-sample), and intervention conducted on a given day is affected by the intervention carried out in the previous day (across all samples). Intervention also reacts to intervention effected two days ago (except in the first sub-sample), and it also reacts to intervention conducted three days ago (except in the first and second sub-sample). The significance of the one, two and three period lags of INT across different sub-samples suggests that the conduct of interventions is clustered. ${ }^{12}$

We next report our baseline estimates of equation (5), the second-stage outcome equation. We estimate this model using the linear LP advocated by Jorda (2005), but without the inverse probability weights. To recall, the linear LP involves estimating the model using linear regression for each period or horizon. For the first horizon, the changes in the JPY/USD in time $t$ is regressed on the contemporaneous term for intervention and up to nine lags selected for the variables intervention and the changes in the JPY/USD exchange rate using the information criterion. For the second horizon, the changes in the JPY/USD in time $t+1$ is regressed on the same (not re-dated) set of explanatory variables. Given that in each horizon, we are interested in the estimated coefficient of the contemporaneous term for intervention, we show the average causal effect of intervention on the changes in the JPY/USD exchange rate from the sequence of estimates for this coefficient, i.e., the intervention effects. ${ }^{13}$ As mentioned before, to mitigate simultaneity bias, we instrumented contemporaneous intervention in the estimation of the linear LP by the predicted values of the first-stage estimates. We also set the horizon to ten days.

Figure 2 depicts the average causal effect of intervention on the changes of the JPY/USD exchange rate across the four samples. There are four panels in Figure 2 corresponding to each sub-sample. The solid line and the blue bands in each panel represent the point estimates and the $95 \%$ confidence bands, respectively. Panel (a) (full sample) shows a negative effect of intervention on the changes of the JPY/USD exchange rate in the first horizon, but this "incorrect" sign of the intervention effect is not significantly different from zero. The rest of the estimates of this effect for subsequent horizons are also not significantly from

\footnotetext{
12 Fatum and Hutchison (2010) make a similar point.

${ }^{13}$ Both variables, the changes in JPY/USD exchange rate and the predicted values of intervention were found to be stationary according to standard ADF unit-root tests.
} 
zero. This also holds for the estimates of the intervention effect across the three sub-samples (Panels (b) to (d)) for which we cannot find any significant influence of intervention. The only exception to this result is a significant negative effect of intervention in period five in Panel (b) (January 1999 to December 2002 sub-sample), but this effect is of the "wrong" sign.

\subsection{Linear LP with Inverse Probability Weights}

Before we present the analysis of the second-stage outcome equation using linear LP with inverse probability weights, we first discuss the results of the estimation of the first-stage intervention reaction function. One of the challenges in specifying these intervention reaction function is that on most days, intervention takes a value of zero because the central bank does not intervene in the foreign exchange market. This implies that the OLS estimates of these reaction functions, such as the baseline estimates we presented earlier, are inconsistent. Modeling the reaction function as a censored variable and estimating using a Tobit model across the four samples overcomes this problem.

We again estimate the first-stage intervention reaction function by first including all explanatory variables in equation (1), then excluding the insignificant explanatory variables, and re-estimating the reduced reaction function across all samples. This time, the common results across all samples is the insignificance of the lone variable, lagged YEAREXR. The Tobit estimates of the reduced reaction functions are presented in Table 2. The significant variables for the full sample (column 1) are lagged EXR and the one and two period lags of INT, and, similar to baseline estimates, the significant variables differ across the three subsamples (columns to four). The significant variables in the reduced estimates suggest that intervention reacts to the previous day changes in the JPY/USD exchange rate (except in the second sub-sample), the 21-day moving average of the exchange rate (MA21EXR) and 1year moving average of the exchange rate (YEAREXR) (except in the third sub-sample for both variables). Intervention conducted on a given day reacts to intervention carried out in the previous day; intervention effected two days ago; and, to intervention made three days ago (except in the first and second sub-samples). Similar to the baseline estimates, interventions are carried out in clusters in view of the significance of the one, two and three period lags of INT across different sub-samples.

We now turn to the linear LP estimates using inverse probability weights, and the results are presented in Figure 3. Again, there are four panels in Figure 3 that corresponds to each sub-sample, and the solid line and blue bands in each panel represent the point estimates and $95 \%$ confidence bands, respectively. The average causal effect of intervention on the changes of the JPY/USD exchange rate in the full sample is shown in Panel (a). The results indicate a significant positive response of the changes in the exchange rate to interventions in the first period. The estimate suggests that an intervention, on average, leads to a $0.26 \%$ increase in the JPY/USD exchange rate. However, the effect of an intervention becomes not significantly different from zero at subsequent horizons. For the first sub-sample (January 1999 to 
December 2002) presented in Panel (b), we also find a significant impact of intervention on the changes in the JPY/USD exchange rate in the first and third periods ${ }^{14}$, and, likewise, this effect is of the correct sign (appreciation of the USD vis-à-vis the JPY). Specifically, we find a $1.04 \%$ and $1.18 \%$ increase in the JPY/USD exchange rate for the first and third periods, respectively. Again, however, the intervention does not have a significant effect in later horizons. Turning to the second sub-sample (January 2003 to March 2004) in Panel (c), the results indicate that intervention does not have a significant influence on the JPY/USD exchange rate at all horizons. Finally, focusing on the third and final sub-sample (September 2010 to December 2011) shown in Panel (d), intervention causes a significant increase in the JPY/USD exchange rate by $0.25 \%$ and $0.44 \%$ in the first and second periods, respectively. However, similar to the results for the full and first sub-samples, the effect of intervention becomes insignificant at later horizons.

\subsection{Robustness Tests}

To test the robustness of our main results, we carry out a number of sensitivity tests. First, we estimate the second-stage linear LP with inverse probability weights across the four samples using shorter lags, i.e., four lags instead of nine. ${ }^{15}$ The estimates of the average causal effects are depicted in Figure A1. We find the results of this sensitivity test to be very similar to the main results across the four samples. Second, because the treatment variable, the amount of intervention, has a skewed distribution in which a substantial proportion of the observations are zero, in order to make a more reasonable assumption that this treatment variable is normally distributed, we transform this variable using a Box-Cox transformation. Though far from perfect, the Box-Cox searches for a transformation of the amount of intervention for which the marginal distribution is the closest to the standard normal. Once the transformation is undertaken, we then again estimate the second-stage linear LP with inverse probability weights across the four samples. The results of this robustness test are depicted in Figure A2. We also find the results of this sensitivity test to be qualitatively identical to the main results across the four samples. Finally, we include a quadratic term of the contemporaneous intervention in the outcome equation and estimate accordingly the LP with inverse probability weights across the four samples. The results are presented in Figure A3. In this robustness test, we still find positive and significant causal effects of intervention on the changes in JPY/USD exchange rate in earlier horizons, and the magnitude of these effects are now slightly higher compared to the main results. All these tests validate our earlier main results.

\section{Conclusion}

The decision to intervene in the foreign exchange market is not a random decision. Deteriorating market conditions can cause an authority's intervention to work against the

\footnotetext{
${ }^{14}$ The intervention effect, however, comes out insignificant at the second period.

${ }^{15}$ Based on the Schwartz information criterion.
} 
success of the said intervention, which can then masquerade in the results as an apparent lack of intervention effect. On the other hand, an intervention authority can select and intervene in periods for which they believe will have a higher likelihood of success. ${ }^{16}$ In this instance, it can then show up in the results as an apparent intervention effect. Self-selection bias represents an internal validity threat that can render empirical results invalid and lead to erroneous conclusions. The main aim of this paper is to carefully evaluate the causal effects of intervention on the changes in the exchange rate, while at the same time address the issue of self-selection, in addition to the well-known problems of simultaneity and censored data that often beset this literature.

Borrowing from the broad treatment effects literature by viewing the changes in the JPY/USD exchange rate as the outcome variable, with the daily amounts of interventions by Japanese monetary authorities in the JPY/USD market as the outcome variable, we build and extend in a continuous treatment setting, the inverse probability weights estimator developed by Jorda and Taylor (2015) and Angrist, Jorda and Kuersteiner (forthcoming) to control for self-selection bias. To the best of our knowledge, this technique has not been previously applied to this literature. This technique is particularly suited to address the problem of selfselection because it simulates a situation of "as if" the decision to intervene had been taken at random by effectively creating a counterfactual or pseudo-population through attaching a higher weight to observations that have lower probabilities of self-selection in the sample, while according less weight to observations that have high probabilities of self-selection. The weights were constructed through an estimation in the first-stage of a censored intervention reaction model.

Looking at the January 1999 to December 2002 sub-sample, we find that intervention had significant effects on the changes in the JPY/USD exchange rate on the same day of the intervention as well as two days after the intervention took place. These effects are in the right direction. In contrast, we find completely insignificant effects of intervention in the January 2003 to March 2004 sub-sample. Finally, turning to the September 2010 to December 2011 sub-sample, we again find significant effects of intervention that lasts one day from the time the intervention took place. These significant effects are also in the correct direction. These results are also robust to various sensitivity tests.

Noting that Japanese intervention activities in the JPY/USD market were described as large and infrequent during the sub-samples January 1999 to December 2002 and September 2010 to December 2011, the finding of significant effects of intervention during these two periods is consistent with evidence in this literature which suggests that only large, infrequent and sporadic interventions are effective in moving the changes in the exchange rate in the desired direction. Furthermore, the finding that the effect of intervention is not long-lasting is in conformity with the earlier finding of Nagayasu (2004).

${ }^{16}$ Dominguez (2003), Fratzscher et al. (2015) cite the example of good knowledge of daily market circumstances that can raise the likelihood of success of intervention. 
The results imply that while intervention is an effective tool, it cannot be regarded as a panacea that can move exchange rates at will and at all times. It can affect the exchange rate only in certain circumstances. These circumstances that surround its capability to affect the exchange rate relates to the size and frequency of foreign exchange intervention. Only large and infrequent interventions can move exchange rates, which then signifies that small and frequent interventions should be avoided. The results we obtain here uses intervention data for an advanced economy with a foreign exchange market that is one of the largest in the world. What does the results entail then for emerging economies in which this policy option occurs more heavily and frequently? One can argue that because foreign exchange markets in these economies are small and less liquid, we can expect that the size of their foreign exchange interventions would have a more considerable impact on exchange rates. For emerging economies that have recently decided to make their data on foreign exchange intervention publicly available, this is a topic worthy of further research. 


\section{References}

Adler, G. and C. Tovar, (2014), "Foreign Exchange Interventions and their Impact on Exchange Rate Levels," Monetaria, pp.1-48.

Angrist, J.; O. Jorda and G. Kuersteiner, (Forthcoming), "Semiparametric Estimates of Monetary Policy Effects: String Theory Revisited," Journal of Business and Economic Statistics.

Almekinders, G. and S. Eijffinger, (1994), "Daily Bundesbank and Federal Reserve Interventions: Are They a Reaction to Changes in the Level and Volatility of the $\mathrm{DM} / \$$ Rate?" Empirical Economics, 19, pp. 111-130.

Almekinders, G., (1995), Foreign Exchange Intervention: Theory and Evidence, Elgar, Brookfield, VT.

Bailie, R.T. and O.F. Humpage, (1992), "Post-Louvre Intervention: Did Target Zones Stabilize the Dollar?" Working Paper, 9203, Federal Reserve Bank of Cleveland.

Bailie, R.T. and W.P. Osterberg, (1997), "Central Bank Intervention and Risk in the Forward Premium," Journal of International Economics, 43, pp. 483-497.

Bordon, A. R.; C. Ebeke and K. Shirono, (2016), "When Do Structural Reforms Work? On the Role of the Business Cycle and Macroeconomic Policies," IMF Working Paper, 16/62. International Monetary Fund.

Brandner, P. and H. Grech, (2005), "Why did Central Banks Intervene in ERMI? The Post1993 Experience," IMF Staff Papers, 52, pp. 120-147.

Diniz, A., (2016), "Effects of Fiscal Consolidations in Latin America," Textos Para Discussão, 423, FGV/EESP - Escola de Economia de São Paulo, Getulio Vargas Foundation, Brazil.

Dominguez, K. and J. Frankel, (1993), "Does Foreign Exchange Intervention Matter? The Portfolio Effect," American Economic Review, 83, pp. 1356-1369.

Dominguez, K., (2003), "The Market Microstructure of Central Bank Intervention," Journal of International Economics, 59 (1), pp. 25-45.

Edison, H., (1993), "The Effectiveness of Central Bank Intervention: A Survey of the Literature After 1982," Special Papers in International Economics, Vol. 18, Princeton University.

Fatum, R. and M. Hutchison, (2006), "Effectiveness of Official Daily Foreign Exchange Market Intervention Operations in Japan," Journal of International Money and Finance, 25, pp. 199-219.

Fatum, R. and M. Hutchison, (2010), "Evaluating Foreign Exchange Intervention: SelfSelection, Counterfactuals and Average Treatment Effects," 29, pp. 570-584.

Fatum, R. and Y. Yamamoto, (2014), "Large Versus Small Foreign Exchange Interventions," Journal of Banking and Finance, 43, pp. 114-123. 
Fratzscher, M.; O. Gloede; L. Menkhoff; L., Sarno and T. Stohr, (2015) "When is Foreign Exchange Intervention Effective? Evidence from 33 Countries," DIW Discussion Papers, 1518. DIW, Berlin.

Galati, G. and P. Disyatat, (2005), "The Effectiveness of Foreign Exchange Intervention in Emerging Market Countries: Evidence from the Czech Koruna," BIS Working Paper, No. 429. Basel: Bank for International Settlements.

Galati, G. and W. Melick, (2002), "Central Bank Intervention and Market Expectations," BIS Papers, No. 10, Basel: Bank for International Settlements.

Galati, G.; W. Melick and M. Micu, (2005), "Foreign Exchange Market Intervention and Expectations: The Yen/Dollar Exchange Rate," Journal of International Money and Finance, 24, pp. 982-1011.

Glynn, A. and K.M. Quinn, (2010), "An Introduction to the Augmented Inverse Propensity Weighted Estimator," Political Analysis, 18 (1), pp. 36-56.

Hillebrand, E. and G. Schnabl, (2004), "The Effects of Japanese Foreign Exchange Intervention: GARCH Estimation and Change Point Detection," International Finance, 0410008, EconWPA.

Hirano, K. and G. Imbens, (2004), "The Propensity Score with Continuous Treatments," In: D.B. Rubin, A. Gelman and X.L. Meng (Eds.), Applied Bayesian Modeling and Causal Inference from Incomplete-Data Perspectives: An Essential Journey with Donald Rubin's Statistical Family, John Wiley, New York, NY, pp. 73-84.

Humpage, O., (1999), "US Intervention: Assessing the Probability of Success," Journal of Money, Credit and Banking, 31, pp. 731-747.

Ito, T., (2003), "Is Foreign Exchange Intervention Effective? The Japanese Experience in the 1990s ," In: P. Mizen (Ed.), Monetary History, Exchange Rates and Financial Markets, Essays in Honour of Charles Goodhart, Vol. 2. Edward Elgar, UK, pp. 126-153.

Ito, T. and T. Yabu, (2007), "What Promotes Japan to Intervene in the Forex Market? A New Approach to a Reaction Function," Journal of International Money and Finance, 26, pp. 193-212.

Jorda, O., (2005), "Estimation and Inference of Impulse Responses by Local Projections," American Economic Review, 95(1), pp. 161-182.

Jorda, O. and A. Taylor, (2015), "The Time for Austerity: Estimating the Average Treatment Effect of Fiscal Policy," Economic Journal, 126, pp. 219-255.

Jorda, O.; M. Schularick and A. Taylor, (2016), "The Great Mortgaging: Housing Finance, Crises and Business Cycles," Economic Policy, pp. 107-152.

Kearns, J. and R. Rigobon, (2005), "Identifying the Efficacy of Central Bank Interventions: Evidence from Australia and Japan," Journal of International Economics, 66, pp. 31-48.

Kim, S.J. and J. Sheen, (2002), "The Determinants of Foreign Exchange Intervention by Central Banks: Evidence from Australia," Journal of International Money and Finance, 21, pp. 619-649. 
Kuvshinov, D. and K. Zimmermann, (2016), "Sovereigns Going Bust: Estimating the Cost Of Default," Bonn Econ Discussion Paper, 01/2016, Bonn Graduate School of Economics, University of Bonn.

Lunceford, J.K. and M. Davidian, (2004), "Stratification and Weighting via the Propensity Score in Estimation of Causal Treatment Effects: A Comparative Study," Statistics in Medicine, 23 (19), pp. 2937-2960.

Nagayasu, J., (2004), "The Effectiveness of Japanese Foreign Exchange Interventions during 1991-2001," Economics Letters, 84, pp. 377-381.

Neely, C., (2008), "Central Bank Authorities' Beliefs about Foreign Exchange Intervention," Journal of International Money and Finance, 27, pp. 1-25.

Robins, J.M.; M.A. Hernan and B. Brumback, (2000), "Marginal Structural Models and Causal Inference in Epidemiology," Epidemiology, 11, 5, pp. 550-560.

Rogers, J.M. and P. Siklos, (2003), "Foreign Exchange Market Intervention in Two Small Open Economies: The Canadian and Australian Experience," Journal of International Money and Finance, 22, pp. 393-416.

Sarno, L. and M. Taylor, (2001), "Official Intervention in the Foreign Exchange Market: Is it Effective and if So, How Does it Work?" Journal of Economic Literature, 34, pp. 839868.

Takagi, S., (2014), "The Effectiveness of Foreign Exchange Market Intervention: A Review of Post-2001 Studies on Japan," Journal of Reviews on Global Economics, 3, pp. 84-100.

Zhang, Z.; J. Zhou; W. Cao and J. Zhang, (2016), "Causal Inference with a Quantitative Exposure," Statistical Methods in Medical Research, 25 (1), pp. 315-335. 
Table 1

Official Japanese Intervention, 1 January 1999 to December 31, 2011

\begin{tabular}{ccccc}
\hline & $\begin{array}{c}\text { Full sample: } \\
\text { January 1999 - } \\
\text { December 2011 }\end{array}$ & $\begin{array}{c}\text { Sample 1: } \\
\text { January 1999 - } \\
\text { December 2002 }\end{array}$ & $\begin{array}{l}\text { Sample 2: } \\
\text { January 2003 } \\
\text { March 2004 }\end{array}$ & $\begin{array}{c}\text { Sample 4: } \\
\text { September 2010 - } \\
\text { December 2011 }\end{array}$ \\
& $(1)$ & $(2)$ & $(3)$ & $(4)$ \\
\hline Total intervention days & 167 & 30 & 129 & 8 \\
Average daily amount & 4,134 & 4,977 & 2,520 & 29,330 \\
Maximum daily amount & 102,426 & 13,211 & 15,568 & 102,426 \\
Minimum daily amount & 1 & 804 & 1 & 2,916 \\
$>1000$ & 121 & 28 & 85 & 8 \\
$>500$ & 21 & 2 & 19 & 0 \\
$>250$ & 5 & 0 & 5 & 0 \\
$>0$ & 20 & 0 & 20 & 0 \\
\hline
\end{tabular}

Notes:

(a) Daily Japanese intervention data obtained from the Japanese Ministry of Finance statistics.

(b) All amounts are in millions of USD. Average daily amount refers to intervention days only.

(c) Daily intervention operations of USD 1000 million or greater: >1000; daily intervention operations of USD 500 million or greater, but less than USD 1000 million: >500; daily intervention operations of USD 250 million or greater, but less than USD 500 million: $>250$; daily intervention operations of less than USD 250 million: $>0$.

Source: Author's calculations. 
Table 2

Intervention Reaction Functions: Tobit Estimates

\begin{tabular}{|c|c|c|c|c|}
\hline & $\begin{array}{l}\text { Full sample: } \\
\text { January } 1999- \\
\text { December } 2011 \\
\qquad \text { (1) }\end{array}$ & $\begin{array}{l}\text { Sample 1: } \\
\text { January 1999- } \\
\text { December } 2002 \\
\text { (2) }\end{array}$ & $\begin{array}{l}\text { Sample 2: } \\
\text { January } 2003- \\
\text { March } 2004 \\
\text { (3) }\end{array}$ & $\begin{array}{l}\text { Sample 4: } \\
\text { September } 2010 \text { - } \\
\text { December } 2011 \\
\text { (4) }\end{array}$ \\
\hline Constant & $\begin{array}{c}-24.33^{\star * *} \\
(1.94)\end{array}$ & $\begin{array}{l}-98.26 \\
(74.80)\end{array}$ & $\begin{array}{l}-445.16 \\
(440.68)\end{array}$ & $\begin{array}{c}-208.71^{* * *} \\
(78.89)\end{array}$ \\
\hline EXR, $t-1$ & $\begin{array}{l}-2.60^{\star * *} \\
(0.805)\end{array}$ & $\begin{array}{l}-3.53^{\star *} \\
(1.62)\end{array}$ & n.a. & $\begin{array}{l}-64.83^{*} \\
(39.09)\end{array}$ \\
\hline MA21EXR, $t-1$ & n.a. & $\begin{array}{l}-63.05^{\star} \\
(34.42)\end{array}$ & $\begin{array}{c}-144.74^{\star *} \\
(62.18)\end{array}$ & n.a. \\
\hline YEAREXR, $t-1$ & n.a. & $\begin{array}{l}79.38^{*} \\
(40.78)\end{array}$ & $\begin{array}{l}238.74^{*} \\
(136.48)\end{array}$ & n.a. \\
\hline INT, $t-1$ & $\begin{array}{c}0.805^{\star * *} \\
(0.123)\end{array}$ & $\begin{array}{c}1.21^{* *} \\
(0.548)\end{array}$ & $\begin{array}{l}0.700^{* *} \\
(0.348)\end{array}$ & $\begin{array}{l}4.49^{* *} \\
(2.18)\end{array}$ \\
\hline INT, $t-2$ & $\begin{array}{c}0.642^{\star * *} \\
(0.116)\end{array}$ & $\begin{array}{l}1.77^{\star \star *} \\
(0.525)\end{array}$ & $\begin{array}{l}0.709^{* *} \\
(0.349)\end{array}$ & $\begin{array}{c}1.07^{\star} \\
(0.585)\end{array}$ \\
\hline INT, $t-3$ & n.a. & n.a. & n.a. & $\begin{array}{c}1.75^{*} \\
(1.02)\end{array}$ \\
\hline $\begin{array}{c}\log L \\
\text { Observations }\end{array}$ & $\begin{array}{c}-1030.69 \\
3193\end{array}$ & $\begin{array}{l}-160.18 \\
986\end{array}$ & $\begin{array}{c}-73.56 \\
307\end{array}$ & $\begin{array}{c}-55.60 \\
327\end{array}$ \\
\hline
\end{tabular}

Notes:

(a) Heteroscedasticity and autocorrelation consistent standard errors in parentheses.

(b) The estimated intervention reaction functions are defined in equation (X) in the text.

(c) The dependent variable, INT, is the official intervention amount in millions of USD.

(d) The independent variables are defined as: EXR is the first-difference of the log of the JPY per USD exchange rate; MA21EXR is the 21-day moving average of the log of the JPY per USD exchange rate; YEAREXR is the 1-year moving average of the log of the JPY per USD exchange rate; and lagged amounts of INT.

(e) n.a. indicates that the variable is omitted due to lack of significance.

${ }^{*}$ significant at $10 \%$ level; ${ }^{* *}$ significant at $5 \%$ level; ${ }^{* * *}$ significant at $1 \%$ level.

Source: Author's calculations. 
Table A1

Intervention Reaction Functions: OLS Estimates

$\begin{array}{llll}\text { Full sample: } & \text { Sample 1: } & \text { Sample 2: } & \text { Sample 4: } \\ \text { January 1999 - } & \text { January 1999 - } & \text { January 2003 - } & \text { September 2010 - } \\ \text { December 2011 } & \text { December 2002 } & \text { March 2004 } & \text { December 2011 }\end{array}$

\begin{tabular}{|c|c|c|c|c|}
\hline & (1) & (2) & (3) & (4) \\
\hline Constant & $\begin{array}{c}0.167^{* * *} \\
(0.049)\end{array}$ & $\begin{array}{c}0.143^{* * *} \\
(0.035)\end{array}$ & $\begin{array}{c}0.504^{* * *} \\
(0.110)\end{array}$ & $\begin{array}{c}0.566 \\
(0.037)\end{array}$ \\
\hline EXR, $t-1$ & $\begin{array}{c}-0.099 * * * \\
(0.032)\end{array}$ & $\begin{array}{c}-0.146^{* * *} \\
(0.047)\end{array}$ & n.a. & $\begin{array}{c}-0.554^{*} \\
(0.297)\end{array}$ \\
\hline INT, $t-1$ & $\begin{array}{l}0.069^{* *} \\
(0.029)\end{array}$ & $\begin{array}{l}0.058^{\star} \\
(0.034)\end{array}$ & $\begin{array}{c}0.332^{* * *} \\
(0.062)\end{array}$ & $\begin{array}{c}0.045^{\star \star \star} \\
(0.015)\end{array}$ \\
\hline INT, $t-2$ & $\begin{array}{l}0.055^{\star *} \\
(0.026)\end{array}$ & n.a. & $\begin{array}{c}0.180^{* * *} \\
(0.040)\end{array}$ & $\begin{array}{l}0.005^{\star} \\
(0.003)\end{array}$ \\
\hline INT, $t-3$ & $\begin{array}{c}0.062^{* * *} \\
(0.016)\end{array}$ & n.a. & n.a. & $\begin{array}{l}0.036^{* *} \\
(0.017)\end{array}$ \\
\hline $\begin{array}{c}R \text {-squared } \\
\text { Observations }\end{array}$ & $\begin{array}{l}0.014 \\
3193\end{array}$ & $\begin{array}{c}0.012 \\
986 \\
\end{array}$ & $\begin{array}{l}0.191 \\
307\end{array}$ & $\begin{array}{c}0.004 \\
327 \\
\end{array}$ \\
\hline
\end{tabular}

\section{Notes:}

(a) Heteroscedasticity and autocorrelation consistent standard errors in parentheses.

(b) The estimated intervention reaction functions are defined in equation $(X)$ in the text.

(c) The dependent variable, INT, is the official intervention amount in millions of USD.

(d) The independent variables are defined as: EXR is the first-difference of the log of the JPY per USD exchange rate; MA21EXR is the 21-day moving average of the log of the JPY per USD exchange rate; YEAREXR is the 1-year moving average of the log of the JPY per USD exchange rate; and lagged amounts of INT.

(e) n.a. indicates that the variable is omitted due to lack of significance.

${ }^{*}$ significant at $10 \%$ level; ${ }^{* *}$ significant at $5 \%$ level; ${ }^{* * *}$ significant at $1 \%$ level. 
Figure 1

Panel A. Daily Intervention Volume

(in millions of USD)

1 January 1999 to March 31, 2004

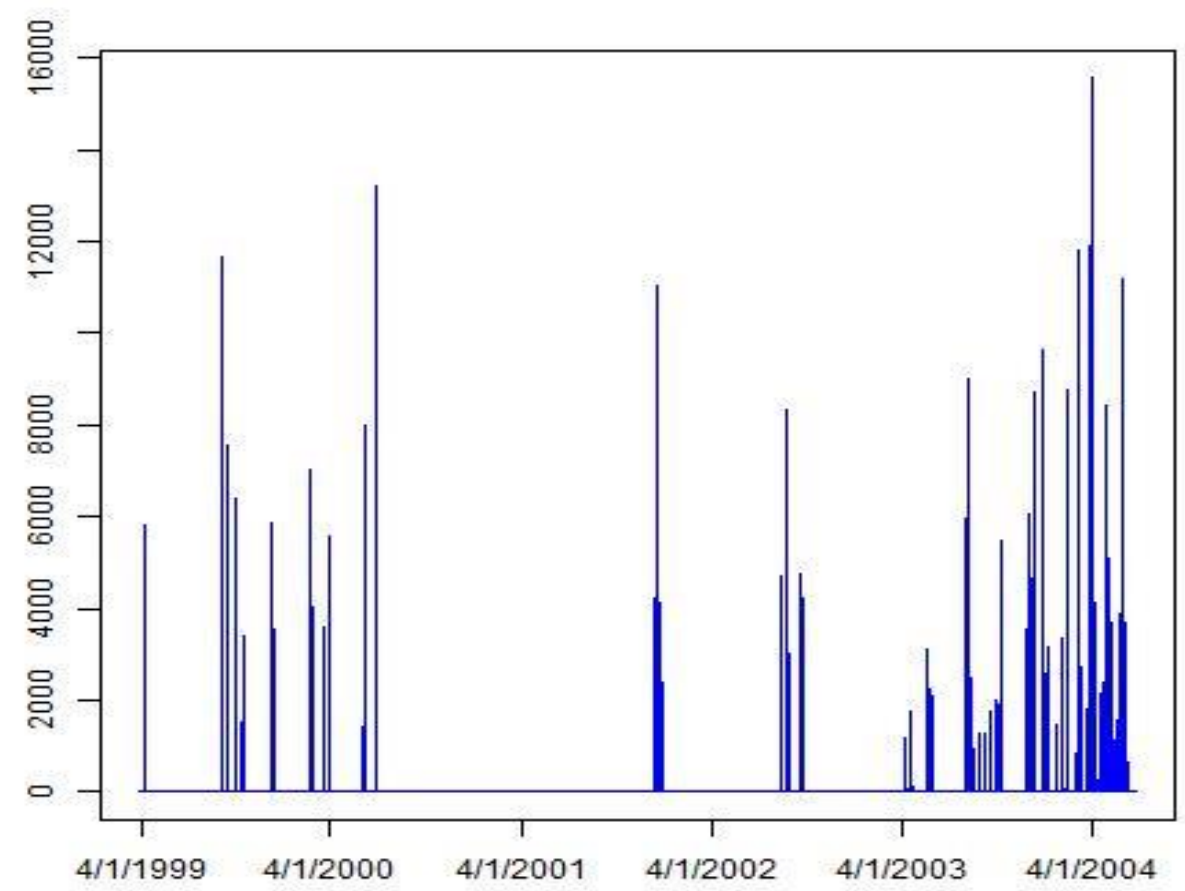

Panel B. Daily Intervention Volume

(in millions of USD)

1 January 1999 to December 31, 2011

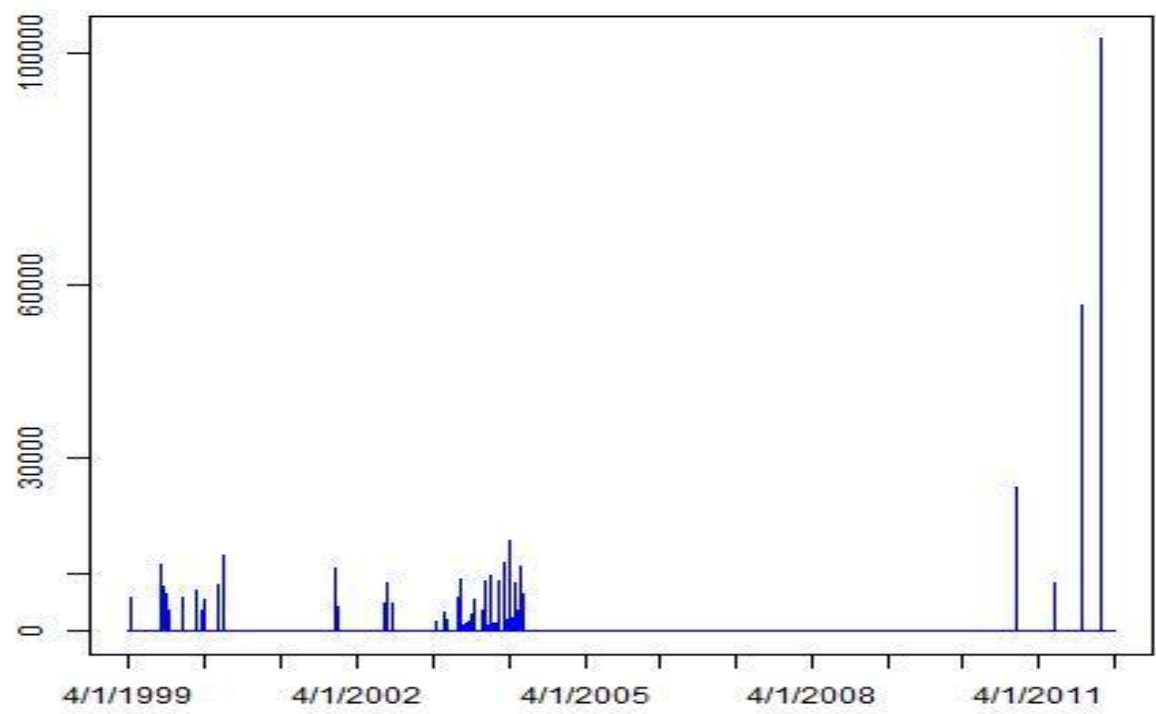

Source: Author's calculations. 


\section{Figure 2}

Average Causal Effect of Intervention on Changes in Yen-US Dollar Rate Estimated using LP (9 lags)
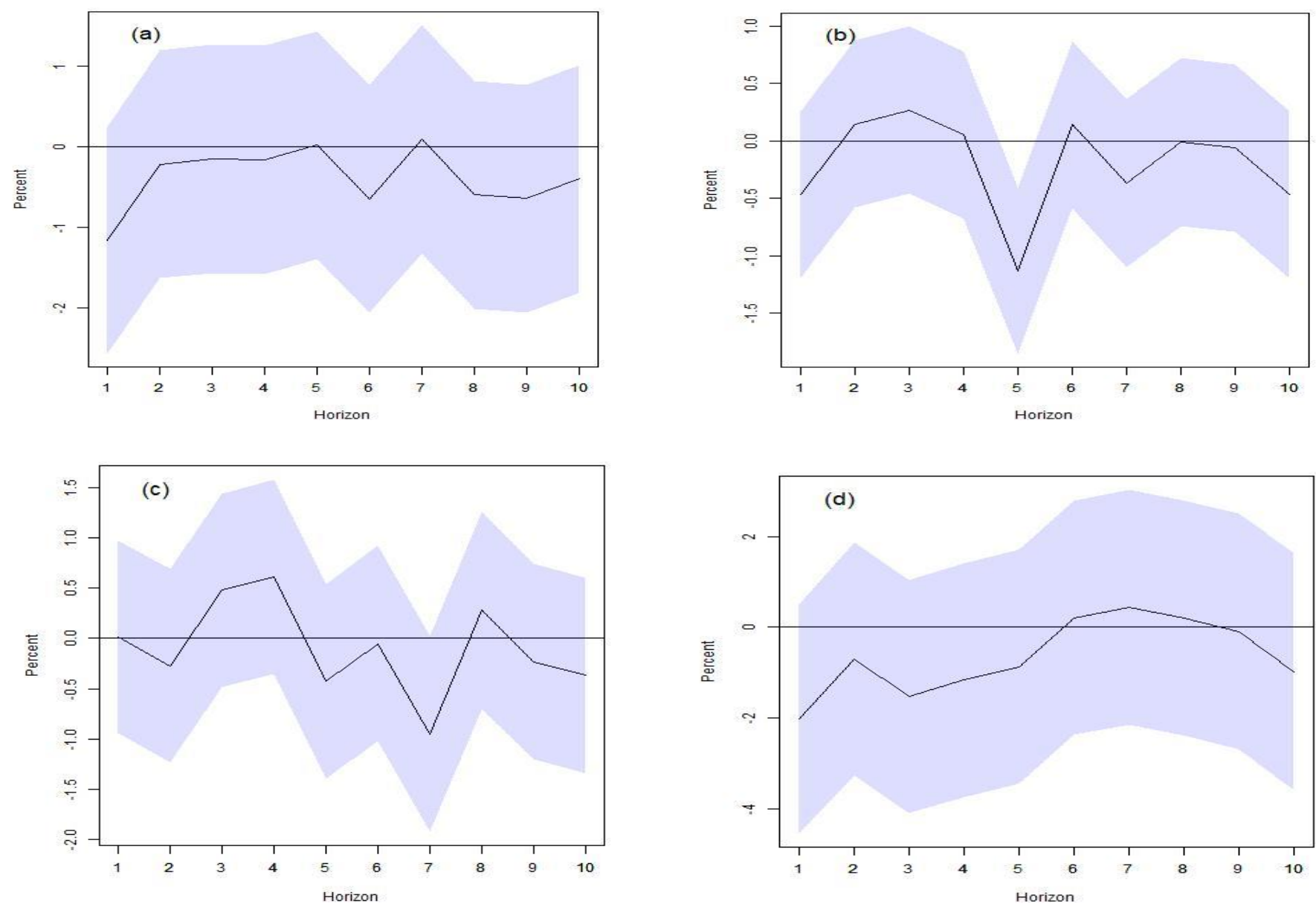

Notes: The shaded area denotes the 95\% confidence interval. Top row: Panels (a) 1 January $1999-31$ December 2011; (b) 1 January 1999 - 31 December 2002. Bottom row: Panels (c) 1 January 2003 - 30 March 2004; (d) 1 September 2010 - 31 December 2011.

Source: Author's calculations. 
Figure 3

Average Causal Effect of Intervention on Changes in Yen-US Dollar Rate Estimated using LP with Inverse Propensity Weights (9 lags)
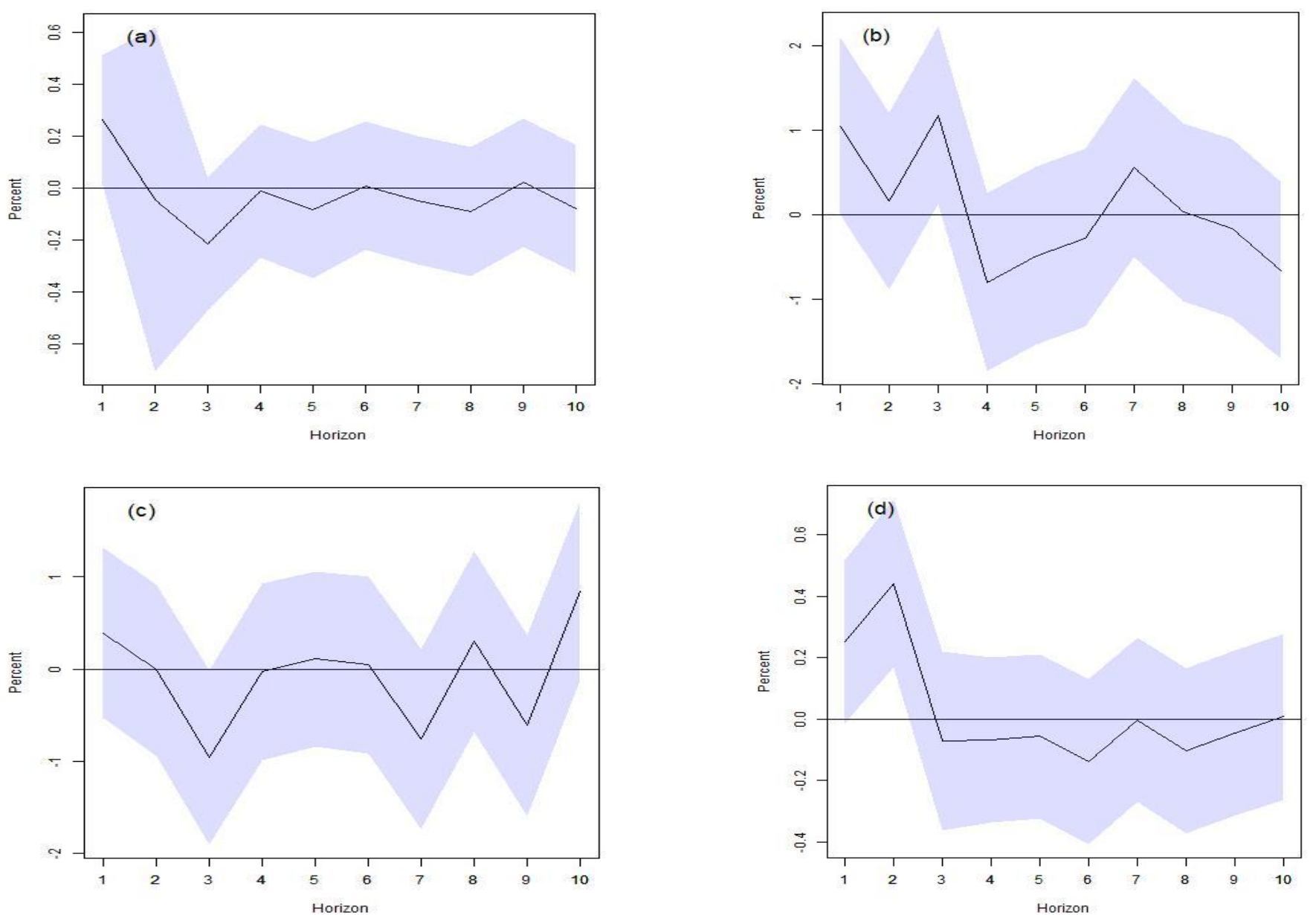

Notes: The shaded area denotes the 95\% confidence interval. Top row: Panels (a) 1 January $1999-31$ December 2011; (b) 1 January 1999 - 31 December 2002. Bottom row: Panels (c) 1 January 2003 - 30 March 2004; (d) 1 September 2010 - 31 December 2011.

Source: Author's calculations. 
Figure A1

Average Causal Effect of Intervention on Changes in Yen-US Dollar Rate Estimated using LP with Inverse Propensity Weights (4 Lags)
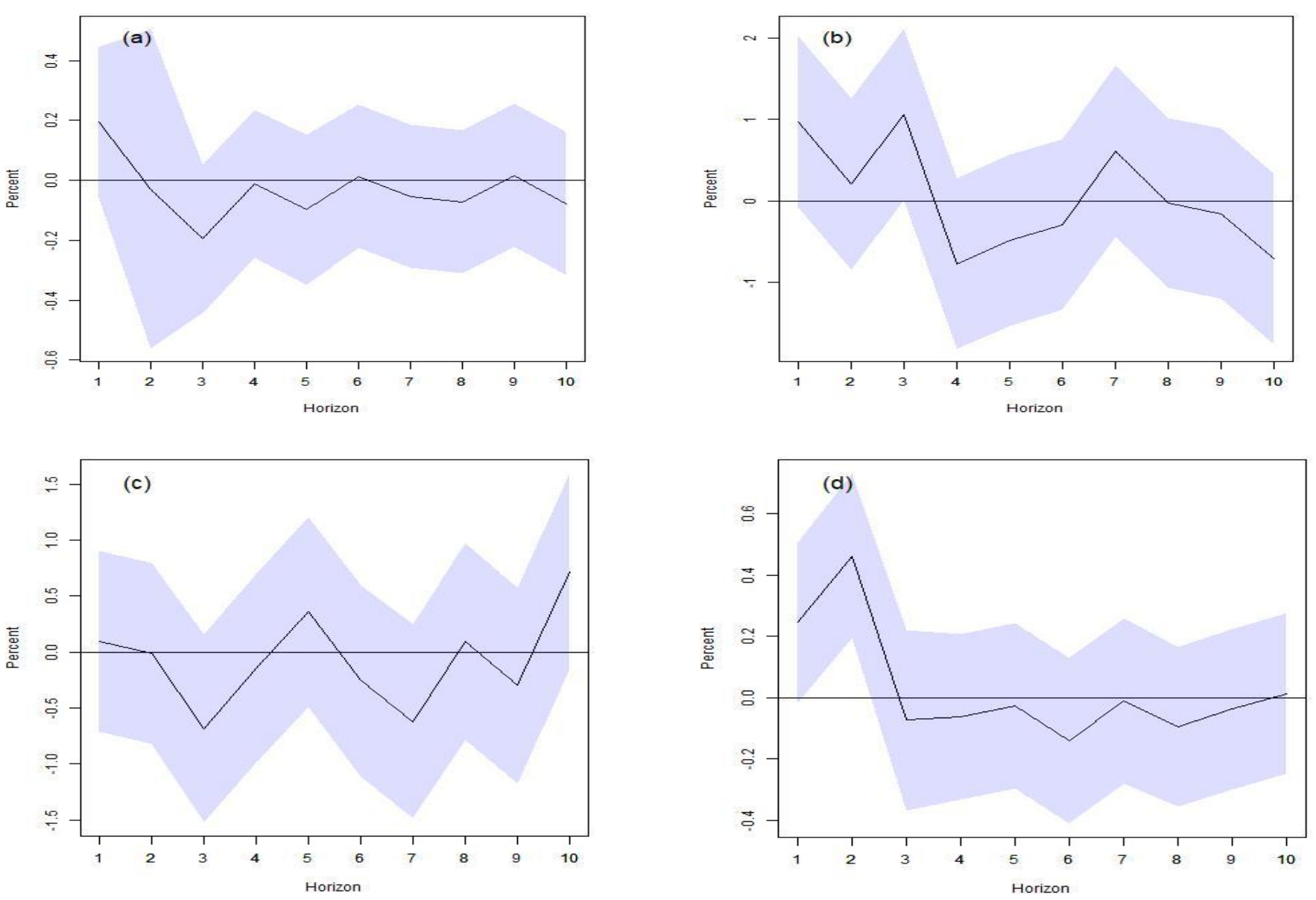

Notes: The shaded area denotes the 95\% confidence interval. Top row: Panels (a) 1 January 1999 - 31 December 2011; (b) 1 January 1999 - 31 December 2002. Bottom row: Panels (c) 1 January 2003 - 30 March 2004; (d) 1 September 2010 - 31 December 2011. Source: Author's calculations. 
Figure A2

Average Causal Effect of Intervention on Changes in Yen-US Dollar Rate Estimated using LP with Inverse Propensity Weights (9 Lags, Box Cox Transform)
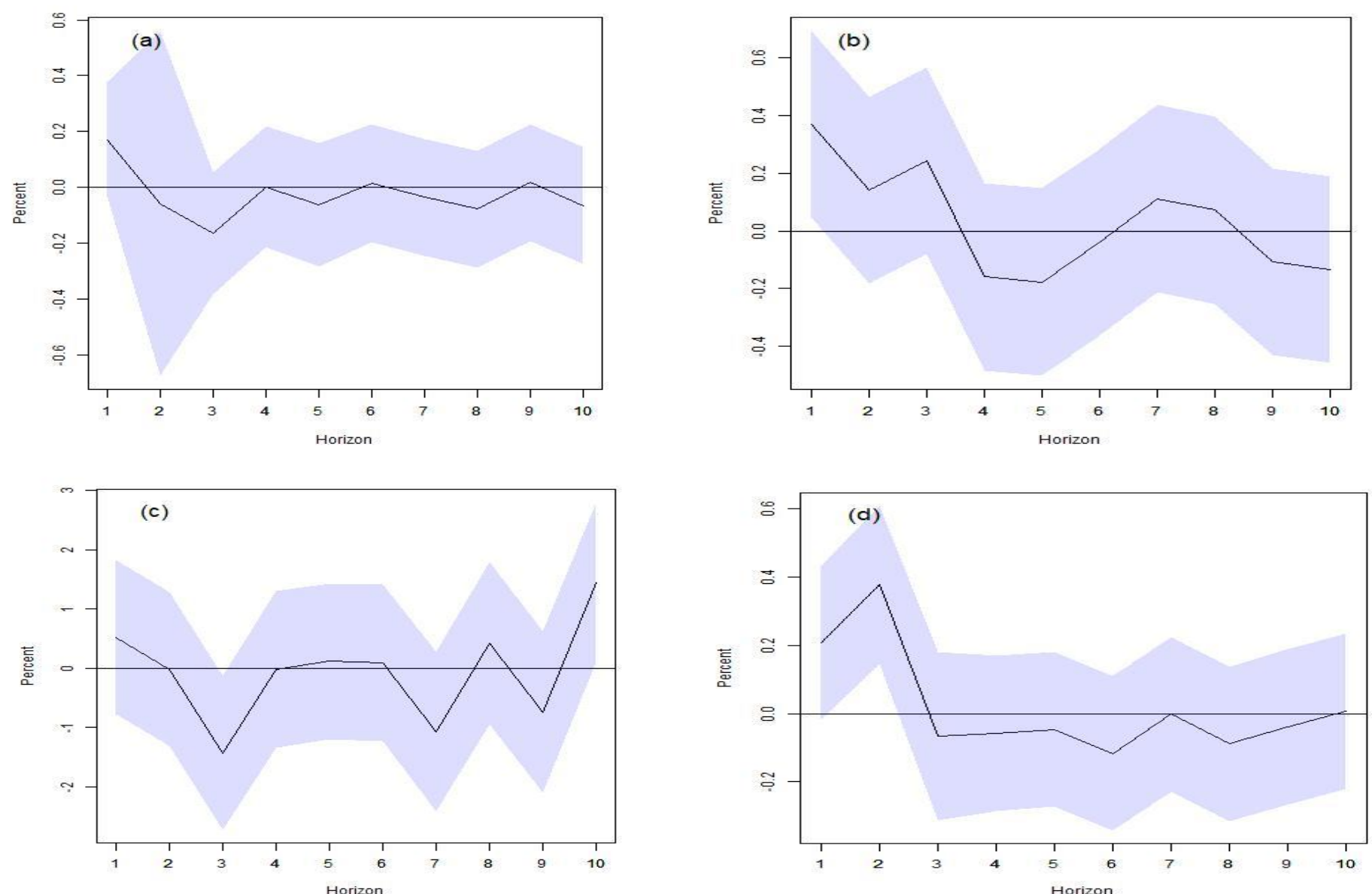

Notes: The shaded area denotes the 95\% confidence interval. Top row: Panels (a) 1 January $1999-31$ December 2011; (b) 1 January 1999 - 31 December 2002. Bottom row: Panels (c) 1 January 2003 - 30 March 2004; (d) 1 September 2010 - 31 December 2011. Source: Author's calculations. 
Figure A3

Average Causal Effect of Intervention on Changes in Yen-US Dollar Rate Estimated using LP with Inverse Propensity Weights (9 Lags, with Squared Contemporaneous Term)
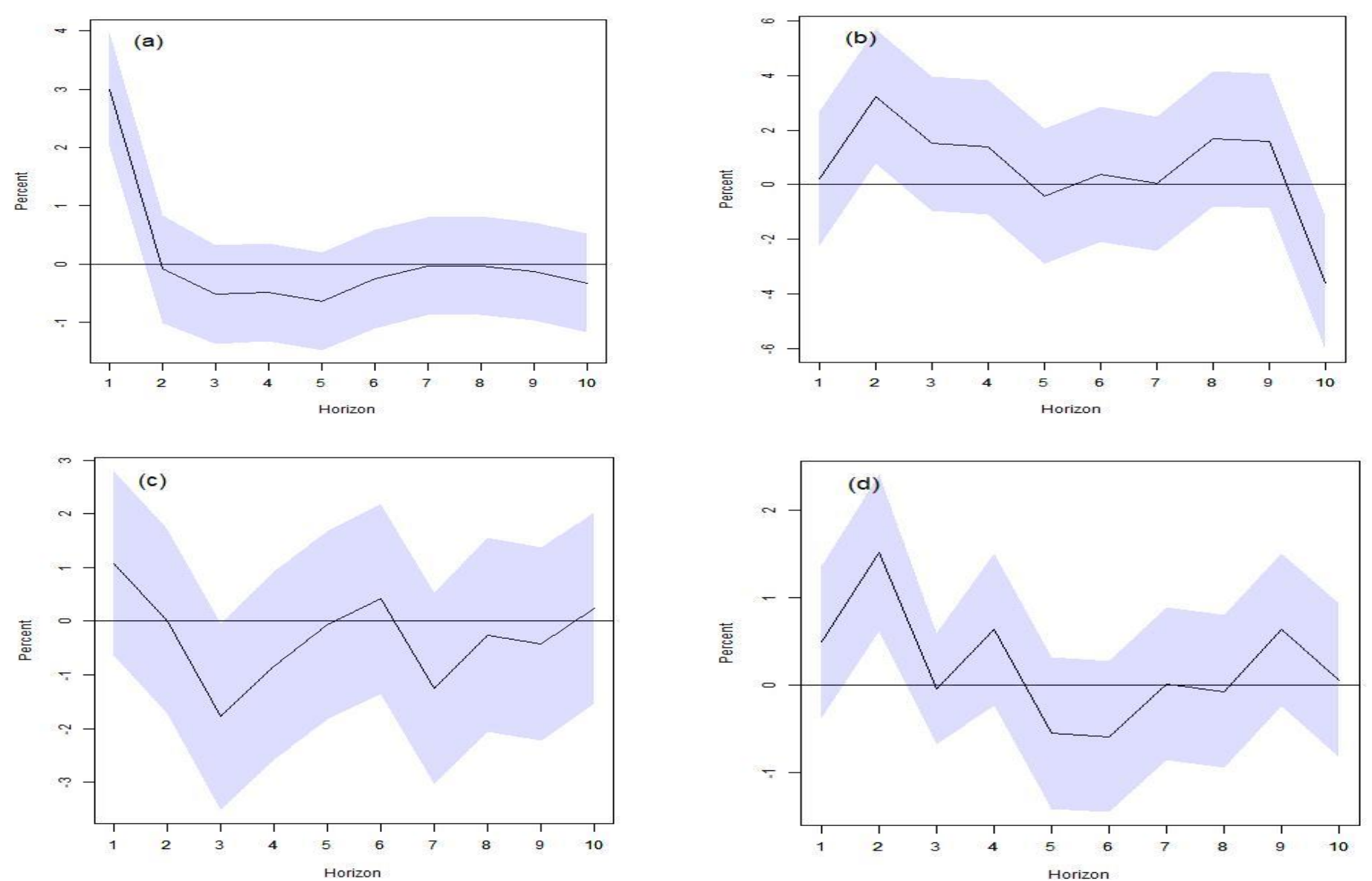

Notes: The shaded area denotes the 95\% confidence interval. Top row: Panels (a) 1 January 1999 - 31 December 2011; (b) 1 January $1999-31$ December 2002. Bottom row: Panels (c) 1 January 2003 - 30 March 2004; (d) 1 September 2010 - 31 December 2011.

Source: Author's calculations. 